\title{
A review of CONSORT reporting Guidelines about comparison groups with a focused discussion on implications for rehabilitation clinical trials
}

William Mark Magnus Levack $\mathrm{PhD}^{1}$, Julia Patrick Engkasan $\mathrm{PhD}^{2}$, Allen W. Heinemann ${ }^{3}$, Stefano Negrini MD ${ }^{4,5}$

${ }^{1}$ Rehabilitation Teaching and Research Unit, Department of Medicine, University of Otago, Wellington, New Zealand

${ }^{2}$ Department of Rehabilitation Medicine, Faculty of Medicine, University of Malaya, Kuala Lumpur, Malaysia

${ }^{3}$ Department of Physical Medicine and Rehabilitation, Feinberg School of Medicine, Northwestern University, Chicago, Illinois USA

${ }^{4}$ Department of Biomedical, Surgical and Dental Sciences, University of Milan "La Statale", Italy

${ }^{5}$ IRCCS Istituto Ortopedico Galeazzi, Milan, Italy

\section{Corresponding author}

William Levack, Rehabilitation Teaching and Research Unit, Department of Medicine, University of Otago, Mein St, Newtown, PO Box 7343, Wellington, 6242, New Zealand.

Email: william.levack@otago.ac.nz. 


\section{Disclosure of interest}

No financial support was provided for this work. We have no known conflicts of interest.

The administration of Cochrane Rehabilitation is supported by a grant from Fondazione Don Gnocchi, Milan, Italy.

\section{Acknowledgements}

We would like to thank the following people for their contribution to this paper: Thorsten Meyer (Ger), Antti Malmivaara (Fin), Walter Frontera (Usa), Frane Grubišić (Cro), Carlotte Kiekens (Bel), Wendy Machalicek (Usa), Aydan Oral (Tur), Gerold Stucki (Swi), Will Taylor (Nzl), Melissa Selb (Swi), Chiara Arienti (Ita), Susan Armijo Olivo (Can), and John Whyte (Usa). We also would like to that the International Society of Physical and Rehabilitation Medicine for their support of the Cochrane Rehabilitation Methodology Meeting in Kobe, Japan. 


\section{Abstract}

Objective: We examined and appraised the CONSORT 2010 Statement and its extension from the perspective of the reporting of comparison groups (i.e., interventions or control conditions against which an experimental intervention is compared) in clinical trials on rehabilitation topics. Design: We downloaded the CONSORT 2010 Statement and all endorsed and unofficial extensions reported on the CONSORT and EQUATOR websites. We extracted all statements on the selection, design, delivery or interpretation of data from comparison groups in clinical trials. We discussed preliminary findings during the Cochrane Rehabilitation Methodology Meeting in Kobe, then further by email before finalizing results. Results: We identified 24 standards reported across the CONSORT 2010 Statement and ten extensions. Overall, these standards address many, but not all, issues related to reporting of comparison groups in rehabilitation trials. Conclusion: We recommend that additional standards be created for the selection of types of comparisons, choices around reporting of "usual care", reporting of intended "mechanisms of control", and reporting a rationale for the hypothesized superiority of one intervention over another when superiority trial design are used. Rehabilitation research would benefit from development of a specific checklist and guidelines to help researchers make best use of existing extensions.

\section{Keywords}

Rehabilitation, control groups, randomized controlled trials, reporting standards 


\section{Introduction}

The choice of a comparison group is an important consideration in the design of any randomized controlled trial (RCT). ${ }^{1-3}$ The reported effect size of experimental interventions is always calculated in reference to the outcomes achieved by a comparison group. Comparison groups that do not appropriately control for variables that are not under investigation will give misleading information about the effectiveness of the experimental intervention. If biases in an RCT favor the experimental intervention, the study can produce artificially inflated effect sizes, making the intervention appear more effective than it is. However, if a comparison group produces unexpected clinical benefits, ones not anticipated by the researchers, the study results could disguise a genuine benefit that could be attributed to the experimental intervention by reducing the reported effect size to a value that is not clinically significant.

As one example of this latter problem, Roth et al. conducted an RCT to test the effectiveness of a resisted expiratory exercise regime for people with complete spinal cord injury at level $\mathrm{T} 1$ or above. ${ }^{4}$ The intervention involved participants blowing with maximal expiratory force against resistance using a handheld device, ten repetitions per session, twice daily for five days each week. For comparison, a control group received a sham intervention that involved the same regime duration and intensity, using the same device, but with the resistance component missing. Six weeks later both the experimental and control groups had improved from baseline on a number of measures of lung function (forced vital capacity, forced expiratory volume in one second, expiratory reserve volume), but with no statistically significant differences between the two groups on most measures. While the researchers found a between-group difference for one of their nine measures of lung function (maximum expiratory pressure), they concluded that any degree of expiratory training might have beneficial effects for people with spinal cord injury. However, they could not confirm this 
conclusion because they did not have a second control group that received no expiratory training. Thus, in attempting to create a sham intervention, these researchers may have created a beneficial intervention - one not routinely offered to people with spinal cord injury. The effectiveness of this new intervention may have disguised the extent of potential benefit of the original experimental intervention.

A strength of this study however was that Roth and colleagues reported in detail on both the experimental and control conditions, making it possible to draw conclusions from their results. This is not always the case. A systematic review on the quality of reporting in stroke rehabilitation research found that experimental groups in clinical trials scored significantly higher $(7.43+/-1.57$ points higher $)$ on the Template for Intervention Description and Replication (TIDieR) checklist (a tool for evaluating the quality of reporting of an intervention) compared to the control groups. ${ }^{5}$ Readers of a clinical trial need to know what researchers are comparing an experimental intervention against in order to interpret the findings from that trial.

Particularly problematic are studies that compare an experimental intervention to "usual care" (also referred to as "conventional care", "standard treatment/care", "customary care", or "treatment as usual"), ${ }^{3,6}$ which can mean anything from minimal or no clinical contact through to intensive multidisciplinary rehabilitation. What counts as usual care can differ from service to service, geographically and over time, making it all the more difficult to compare study findings if further information about the content of usual care is not provided. Clinical trials can also differ depending on whether usual care is offered to both the experimental group and the comparison group (i.e., the experimental intervention is offered as a supplement to usual care) or as an alternative to usual care (i.e., the experimental intervention is tested in a head-to-head comparison against usual care). Usual care may also be offered alongside a sham intervention in order to control for potential behavioral responses 
that the participants might have to the special treatment provided during the experimental intervention. Furthermore, some clinical trials compare two or more active interventions, with no control group per se, to determine which approach is more effective where neither is considered a 'usual' approach to care. Figure 1 provides an overview of common types of comparisons made in clinical trials in rehabilitation.

The selection of comparison groups can have a large influence over the reported effectiveness of experimental interventions. This influence is compounded, often in unpredictable ways, when findings from multiple studies are combined in a meta-analysis. In a recent analysis of the management control groups in a selection of Cochrane reviews on neurorehabilitation interventions, we found that over half of all clinical trials $(53 \% ; 188 / 358)$ contributing to selected meta-analyses involved studies with some variant of a "usual care" control group. ${ }^{1}$ Furthermore, $58 \%$ of meta-analyses selected for analysis pooled data from studies where the control groups received a range of active treatments. ${ }^{1}$ Inadequate reporting on the choice, use, and influence of comparison groups in clinical trials can significantly undermine the quality and utility of the research that underpins evidence-based practice in rehabilitation.

In order to address these and other problems in clinical research, international groups of editors and researchers have worked to established standards for the reporting of clinical trials. The foremost of these is the Consolidated Standards of Report Trials (CONSORT) Statement, initially published in $1996^{7}$ and updated in $2010,{ }^{8}$ with a number of extensions published over the years. The CONSORT statement, which has now been adopted by over 600 journals and editorial groups, has been attributed with substantially improving the quality of reporting of clinical trials. ${ }^{9,10}$ However, as rehabilitation research has its own nuances and 
challenges, ${ }^{11,12}$ it is worth considering the extent to which the CONSORT statement and its extensions meet the reporting needs of the rehabilitation community. The aim of this review was to collate information on the CONSORT 2010 Statement and all current extensions about the reporting of comparison groups in clinical trials, and to evaluate these standards from the perspective of rehabilitation research. In this paper, we use the term "experimental intervention" to refer to the active treatment that is primarily under investigation in a clinical trial and "comparison intervention" to refer to the established intervention or control intervention against which the experimental intervention is compared.

\section{Method}

In October 2019, we downloaded the CONSORT 2010 Statement and all currently endorsed and unofficial extensions to the CONSORT statement published on the CONSORT (http://www.consort-statement.org/) and EQUATOR websites (http://www.equatornetwork.org). We downloaded all checklists, explanations and elaboration documents referenced on these websites, and reviewed the reference lists of these documents for relevant publications on their development. We included extensions to the CONSORT 2010 Statement if the extension or supporting publications included any information about reporting on the selection, design, delivery or interpretation of data from a comparison group in a clinical trial. We excluded extensions that were about interventions not specifically related to rehabilitation, using the pragmatic definition of rehabilitation developed by Cochrane Rehabilitation for the purpose categorizing rehabilitation-related reviews in the Cochrane library. ${ }^{13}$

We reviewed each CONSORT statement and extension, plus all explanatory and background documents to these statements and extensions, extracting data pertaining to the reporting of comparison groups in clinical trials. We collated these reporting standards and 
analyzed them with reference to their application to rehabilitation research. We arrived at the summary and analysis of these standards through discussion. To aid the reader a glossary of terms related to trial design is provided in Table 1.

\section{Results}

In addition to the CONSORT 2010 Statement, we our review identified 20 official and 3 unofficial extensions. We excluded the official extensions on N-of-1 trials, ${ }^{14}$ pilot and feasibility trials, ${ }^{15,16}$ patient reported outcomes (CONSORT-PRO),${ }^{17}$ harms,${ }^{18}$ randomised crossover trial reporting, ${ }^{19}$ and pain ${ }^{20}$, and the unofficial extension for behaviour medicine ${ }^{21}$ and occupational therapy, ${ }^{22}$ as these extensions did not contain additional recommendations regarding reporting on comparison groups. We also excluded the official extensions herbal medicinal intervention, ${ }^{23,24}$ Chinese herbal medicines, ${ }^{25}$ and orthodontics, ${ }^{26}$ and the unofficial extension for homeopathic treatments, ${ }^{27}$ as these extension are not relevant to rehabilitation interventions. Our review therefore included the original CONSORT 2010 Statement and 10 official extensions for data extraction. We identified 24 specific standards related to the reporting of comparison in clinical trials from the CONSORT 2010 Statement and included extensions (see Table 2).

Out of 24 recommendations retrieved that related to reporting on comparison groups, 17 focused on the material and methods section, 2 each on the abstract, introduction/background results and discussion, and one on the title. Overall, the CONSORT 2010 Statement and its extensions address many issues related to the reporting of comparison groups in rehabilitation trials, although these issues are addressed over multiple documents. 
The CONSORT extension for within person trials propose authors included information on comparison groups in the title, ${ }^{28}$ while the extension for abstracts proposed that authors should report both the experiment and comparison intervention and the number of participants in the abstract. ${ }^{29}$ Two of other CONSORT extensions introduced requirements related to reporting the rationale for the selection of comparisons in a clinical trial. $^{30,31}$ In particular, the extension for non-inferiority and equivalence trials suggested that authors provide the rationale for benefits of the experimental intervention over the comparison invention, which should include information on the established evidence for the effectiveness of the comparison intervention. ${ }^{30}$ The extension for multi-arm, parallel-group randomized trials recommended that authors provide a rationale for each comparison they intended to analyze, clearly highlighting which comparison out of multiple options they considered their primary comparison. ${ }^{31}$

The CONSORT extension for pragmatic trials advocated in favor of "usual care" comparison groups, where the objective of the research is to examine the effectiveness of an experimental intervention in a "real world" rather than artificially constrained setting. ${ }^{32}$ The CONSORT 2010 Statement, and many extensions, specify that where authors use "usual care" as a comparison they should provide a thorough description of what this care involved - with an equal degree of detail as for their experimental intervention. The extension for social and psychological interventions takes this recommendation further, recommending that: "Authors should avoid the sole use of labels such as 'treatment as usual' or 'standard care' because they are not uniform across time and place" (p.7). ${ }^{33}$

Since many rehabilitation interventions would meet the criteria for being "complex" 34 , we found relevant the recommendation of the CONSORT extension for social and psychological interventions, which state that authors should report the expected mechanisms 
of action for experimental or comparison interventions under investigation, preferably in the trial registration and protocol. ${ }^{33}$

As for the results section, the extension for multi-arm parallel-group randomized trials emphasized the need to report on the period of recruitment and follow up for all groups. ${ }^{31}$ The extensions for social and psychological interventions include suggestions for the concurrent reporting of qualitative results to discuss the differences between experimental and comparison group in terms of mechanism of effect or unexpected results. ${ }^{33}$ Only the extension for non-pharmacologic treatment interventions included additional recommendations on what to report in the discussion section, specifically on the influence of choice of comparison and generalisability. ${ }^{35}$

\section{Discussion}

The reporting of comparison groups is a major topic in the CONSORT 2010 Statement and its extensions. Many of the issues related to rehabilitation interventions are addressed in these documents, though no single guideline addresses all the relevant issues. Moreover, some of the reporting recommendations are not applicable to rehabilitation, and should be interpreted according to the type of intervention or programs proposed. The type of comparison is a key consideration in the design of all trials, and has implications for the interpretation of its results (see Table 1). None of the extensions to the CONSORT 2010 statement clearly address this issue, which could be an area to address in specific checklist for rehabilitation research. Below we discuss several other key issues related to the reporting of comparison groups in rehabilitation research arising from our analyses of the CONSORT 2010 statement and its extensions. 
"Usual care" interventions have an important part to play in rehabilitation research. Unlike surgical or pharmaceutical interventions, it is often impossible and unethical to discontinue rehabilitation interventions. Even when a health professional does not provide rehabilitation, patient or their family may initiate rehabilitation-like activities on their own. Pragmatic trials avoid highly standardized interventions for experimental and comparison conditions in order to reflect the variability in everyday practice. The authors of the CONSORT extension for pragmatic trial concluded that "trial results are likely to be more widely applicable if the participants, communities, practitioners, or institutions were not narrowly selected; if the intervention was implemented without intense efforts to standardise it; if the comparator group received care or other interventions already widely used" (p.7). ${ }^{32}$ The problem therefore is not the use of "usual care" as a comparison intervention or even as a label for a comparison group, but rather the insufficient reporting of what constitutes "usual care" when it is a control condition.

A number of problems exist, however, regarding the best approach to reporting "usual care" interventions in rehabilitation trials. First, it can be difficult to decide what might be the essential elements of usual care to report. Should the reporting of usual care be limited to services provided by rehabilitation health providers? Should it include reporting on privately funded services outside of rehabilitation health services (e.g., public gym membership and coaching, alternative health interventions, counselling provided by churches or other community groups)? Secondly, it can be difficult and costly to gather information about what health care services a study participant has accessed, particularly over a long period and if researchers use participant recall to collect data. Third, guidelines for reporting on interventions, such as TIDieR, ${ }^{36}$ are not well suited to describe "usual care" in all contexts. New tools and guidelines to describe key feature of "usual care" are required. 


\section{Mechanisms of control}

The CONSORT extensions for social and psychological interventions addresses the need to report a theoretical rationale for the mechanism of effect for experimental interventions. ${ }^{33}$ A mechanism of effect is the hypothesized way that an intervention achieves the intended improvement in the health outcomes of interest. We argue that there is also a need to report a rationale for how researchers believe a comparison group may control for sources of biases - what we have begun to refer to as "a mechanism of control". We suggest this addition because different types of comparison groups control for different types of bias. ${ }^{1}$ Control groups can include no treatment controls, wait list controls, sham or placebo controls, attention controls, and variations on "usual care" controls - each of which may control for different kinds of bias, with different degrees of success. ${ }^{1}$ There may be value therefore in developing standardized terminology around types of control groups and their characteristics.

Furthermore, assumptions about participant responses to different kinds of control conditions need to be evaluated and reported. For instance, research into understanding the Hawthorne effect (a commonly cited source of observation bias) has demonstrated how unpredictable this effect can be in terms of effect size and contextual factors affecting it, ${ }^{37-41}$ so a more robust understanding of these effects is needed in rehabilitation research. It is advisable that researchers also check that control interventions do not include any of the active elements of an experimental intervention, such as strategies to influence patient motivation, engagement, outcome expectancy, self-efficacy, emotional state, or to influence patient-health professional relationships. ${ }^{42}$ Ideally, these assumptions ought to be tested in preliminary or pilot studies, and published prior to the design of a fully powered clinical trial where they features as comparison interventions. 
The CONSORT extension for non-inferiority and equivalence trials provides excellent guidance on the need to report a rationale for the seletion of comparison groups when using non-inferiority and equivalence designs. ${ }^{30}$ However, we recommend that this requirement ought to be extended to studies with superiority designs - an issue that is not addressed in the CONSORT 2010 statement or any of its extensions. Specifically, we recommend that researchers ought to report a rationale not only for how the experimental intervention might work, but also why the authors consider it to be potentially more effective than the comparison intervention. For example: if a study was to test exercises for people after stroke delivered via a robotic assistance or virtual reality in comparison to exercises delivered via a standard gym-based physiotherapy regime, a rationale ought to be provided to justify why the experimental intervention might produce better results than the standard intervention. If no rationale for superiority can be provide, then an equivalence or noninferiority design might be more justifiable, and the researcher ought to follow the CONSORT extensions. ${ }^{30}$

\section{Conclusion}

For issues related to comparison groups, the needs of rehabilitation researchers might be best addressed by an addition to the CONSORT statement for non-pharmacologic interventions, ${ }^{35}$ particularly those on social and psychological interventions, ${ }^{33,43-45}$ which are areas of health science that share many of the same methodological challenges as rehabilitation research. Furthermore, justification and description of the choice of comparison groups is critical. Researchers should report this information in their methods and background sections so that readers of the research report understand the choices made and justification for the design. 
Finally, rehabilitation research will benefit from the development of a specific checklist and guidelines to help researchers make best use of existing extensions to the CONSORT statement. 


\section{References}

1. Levack WMM, Martin RA, Graham FP, Hay-Smith EJC. Compared to what? An analysis of the management of control groups in Cochrane reviews in neurorehabilitation. Eur J Phys Rehabil Med. 2019;55(3):353-63.

2. Hart T, Fann JR, Novack TA. The dilemma of the control condition in experiencebased cognitive and behavioural treatment research. Neuropsychol Rehabil. 2008;18(1):1-21.

3. Hart T. Challenges in the evaluation of neuropsychological rehabilitation effects In: Wilson BA, Winegardner J, van Heugten CM, Ownsworth T, editors. Neuropsychological Rehabilitation: The International Handbook. London: Francis \& Taylor Group; 2017. p. 55968.

4. Roth EJ, Stenson KW, Powley S, Oken J, Primack S, Nussbaum SB, et al. Expiratory muscle training in spinal cord injury: a randomized controlled trial. Arch Phys Med Rehab. 2010;91(6):857-61.

5. Lohse KR, Pathania A, Wegman R, Boyd LA, Lang CE. On the reporting of experimental and control therapies in stroke rehabilitation trials: a systematic review. Arch Phys Med Rehabil. 2018;99(7):1424-32.

6. Brigham GS, Feaster DJ, Wakim PG, Dempsey CL. Choosing a control group in effectiveness trials of behavioral drug abuse treatments. J Subst Abuse Treat. 2009;37(4):388-97.

7. Begg C, Cho M, Eastwood S, Horton R, Moher D, Olkin I, et al. Improving the quality of reporting of randomized controlled trials: the CONSORT statement. JAMA. 1996;276(8):637-9.

8. Schulz KF, Altman DG, Moher D. CONSORT 2010 statement: updated guidelines for reporting parallel group randomised trials. BMC Med. 2010;8:18. 
9. Devereaux P, Manns BJ, Ghali WA, Quan H, Guyatt GH. The reporting of methodological factors in randomized controlled trials and the association with a journal policy to promote adherence to the Consolidated Standards of Reporting Trials (CONSORT) checklist. Control Clin Trials. 2002;23(4):380-8.

10. Turner L, Shamseer L, Altman DG, Weeks L, Peters J, Kober T, et al. Consolidated standards of reporting trials (CONSORT) and the completeness of reporting of randomised controlled trials (RCTs) published in medical journals. Cochrane Database Syst Rev. 2012(11).

11. Levack WMM, Meyer T, Negrini S, Malmivaara A. Cochrane Rehabilitation Methodology Committee: An international survey of priorities for future work. Eur J Phys Rehabil Med. 2017;53(5):814-7.

12. Levack WM, Malmivaara A, Meyer T, Negrini S. Methodological problems in rehabilitation research. Report from a Cochrane Rehabilitation Methodology Meeting. Eur J Phys Rehabil Med. 2019;55(3):319-21.

13. Levack WMM, Rathore FA, Pollet J, Negrini S. One in 11 Cochrane reviews are on rehabilitation interventions, according to pragmatic inclusion criteria developed by Cochrane Rehabilitation. Arch Phys Med Rehabil. 2019;100(8):1492-8.

14. Vohra S, Shamseer L, Sampson M, Bukutu C, Schmid CH, Tate R, et al. CONSORT extension for reporting N-of-1 trials (CENT) 2015 Statement. BMJ. 2015;350:h1738.

15. Eldridge SM, Chan CL, Campbell MJ, Bond CM, Hopewell S, Thabane L, et al. CONSORT 2010 statement: extension to randomised pilot and feasibility trials. BMJ. 2016;355:i5239.

16. Thabane L, Hopewell S, Lancaster GA, Bond CM, Coleman CL, Campbell MJ, et al. Methods and processes for development of a CONSORT extension for reporting pilot randomized controlled trials. Pilot Feasibility Stud. 2016;2:25. 
17. Calvert M, Blazeby J, Altman DG, Revicki DA, Moher D, Brundage MD. Reporting of patient-reported outcomes in randomized trials: the CONSORT PRO extension. JAMA. 2013;309(8):814-22.

18. Ioannidis JP, Evans SJ, Gøtzsche PC, O'neill RT, Altman DG, Schulz K, et al. Better reporting of harms in randomized trials: an extension of the CONSORT statement. Ann Intern Med. 2004;141(10):781-8.

19. Dwan K, Li T, Altman DG, Elbourne D. CONSORT 2010 statement: extension to randomised crossover trials. BMJ. 2019;366:14378.

20. Gewandter JS, Eisenach JC, Gross RA, Jensen MP, Keefe FJ, Lee DA, et al. Checklist for the preparation and review of pain clinical trial publications: a pain-specific supplement to CONSORT. Pain Rep. 2019;4(3):e621.

21. Davidson KW, Goldstein M, Kaplan RM, Kaufmann PG, Knatterud GL, Orleans CT, et al. Evidence-based behavioral medicine: what is it and how do we achieve it? 2003;26(3):161-71.

22. Nelson DL, Mathiowetz V. Randomized controlled trials to investigate occupational therapy research questions. 2004;58(1):24-34.

23. Gagnier JJ, Boon H, Rochon P, Moher D, Barnes J, Bombardier C. Recommendations for reporting randomized controlled trials of herbal interventions: explanation and elaboration. J Clin Epidemiol. 2006;59(11):1134-49.

24. Gagnier J, Boon H, Rochon P, Barnes J, Moher D, Bombardier C. Reporting random controlled trials of herbal medicines. Explore (NY). 2006;2(2):143-9.

25. Cheng C-w, Wu T-x, Shang H-c, Li Y-p, Altman DG, Moher D, et al. CONSORT extension for Chinese herbal medicine formulas 2017: Recommendations, explanation, and elaboration. Ann Intern Med. 2017;167(2):112-21. 
26. Pandis N, Fleming PS, Hopewell S, Altman DG. The CONSORT Statement: Application within and adaptations for orthodontic trials. Am J Orthod Dentofacial Orthop. 2015;147(6):663-79.

27. Dean ME, Coulter MK, Fisher P, Jobst KA, Walach H. Reporting data on homeopathic treatments (RedHot): a supplement to CONSORT. J Altern Complement Med. 2007;13(1):19-23.

28. Pandis N, Chung B, Scherer RW, Elbourne D, Altman DG. CONSORT 2010 statement: extension checklist for reporting within person randomised trials. BMJ. 2017;357:j2835.

29. Hopewell S, Clarke M, Moher D, Wager E, Middleton P, Altman DG, et al. CONSORT for reporting randomized controlled trials in journal and conference abstracts: explanation and elaboration. PLoS Med. 2008;5(1):e20.

30. Piaggio G, Elbourne DR, Altman DG, Pocock SJ, Evans SJ, Group C. Reporting of noninferiority and equivalence randomized trials: an extension of the CONSORT statement. JAMA. 2006;295(10):1152-60.

31. Juszczak E, Altman DG, Hopewell S, Schulz K. Reporting of multi-arm parallelgroup randomized trials: extension of the CONSORT 2010 Statement. JAMA. 2019;321(16):1610-20.

32. Zwarenstein M, Treweek S, Gagnier JJ, Altman DG, Tunis S, Haynes B, et al. Improving the reporting of pragmatic trials: an extension of the CONSORT statement. BMJ. 2008;337:a2390.

33. Grant S, Mayo-Wilson E, Montgomery P, Macdonald G, Michie S, Hopewell S, et al. CONSORT-SPI 2018 Explanation and Elaboration: guidance for reporting social and psychological intervention trials. Trials. 2018;19(1):406. 
34. Craig P, Dieppe P, Macintyre S, Michie S, Nazareth I, Petticrew M. Developing and evaluating complex interventions: the new Medical Research Council guidance BMJ. 2008;337:979-83.

35. Boutron I, Altman DG, Moher D, Schulz KF, Ravaud P. CONSORT statement for randomized trials of nonpharmacologic treatments: a 2017 update and a CONSORT extension for nonpharmacologic trial abstracts. Ann Intern Med. 2017;167(1):40-7.

36. Hoffmann TC, Glasziou PP, Boutron I, Milne R, Perera R, Moher D, et al. Better reporting of interventions: template for intervention description and replication (TIDieR) checklist and guide. BMJ. 2014;348:g1687.

37. Paradis E, Sutkin G. Beyond a good story: from Hawthorne Effect to reactivity in health professions education research. Med Educ. 2017;51(1):31-9.

38. Levitt SD, List JA. Was there really a Hawthorne effect at the Hawthorne plant? An analysis of the original illumination experiments. Am Econ J Appl Econ. 2011;3(1):224-38.

39. Bramel D, Friend R. Hawthorne, the myth of the docile worker, and class bias in psychology. Am Psychol. 1981;36(8):867.

40. Adair JG, Sharpe D, Huynh C-L. Hawthorne control procedures in educational experiments: A reconsideration of their use and effectiveness. Rev Educ Res. 1989;59(2):215-28.

41. McCambridge J, Witton J, Elbourne DR. Systematic review of the Hawthorne effect: new concepts are needed to study research participation effects. J Clin Epidemiol. 2014;67(3):267-77.

42. Di Blasi Z, Harkness E, Ernst E, Georgiou A, Kleijnen J. Influence of context effects on health outcomes: a systematic review. Lancet. 2001;357(9258):757-62. 
43. Grant SP, Mayo-Wilson E, Melendez-Torres G, Montgomery P. Reporting quality of social and psychological intervention trials: a systematic review of reporting guidelines and trial publications. PloS One. 2013;8(5):e65442.

44. Mayo-Wilson E, Grant S, Hopewell S, Macdonald G, Moher D, Montgomery P. Developing a reporting guideline for social and psychological intervention trials. Trials. 2013;14(1):242.

45. Montgomery P, Grant S, Mayo-Wilson E, Macdonald G, Michie S, Hopewell S, et al. Reporting randomised trials of social and psychological interventions: the CONSORT-SPI 2018 Extension. Trials. 2018;19(1):407.

46. Campbell MK, Piaggio G, Elbourne DR, Altman DG. Consort 2010 statement: extension to cluster randomised trials. BMJ. 2012;345:e5661.

47. Moher D, Hopewell S, Schulz KF, Montori V, Gøtzsche PC, Devereaux P, et al. CONSORT 2010 explanation and elaboration: updated guidelines for reporting parallel group randomised trials. BMJ. 2010;340:c322.

48. MacPherson H, Altman DG, Hammerschlag R, Youping L, Taixiang W, White A, et al. Revised standards for reporting interventions in clinical trials of acupuncture (STRICTA): extending the CONSORT statement. PLoS Med. 2010;7(6):e1000261.

49. Welch VA, Norheim OF, Jull J, Cookson R, Sommerfelt H, Tugwell P. CONSORTEquity 2017 extension and elaboration for better reporting of health equity in randomised trials. BMJ. 2017;359:j5085. 


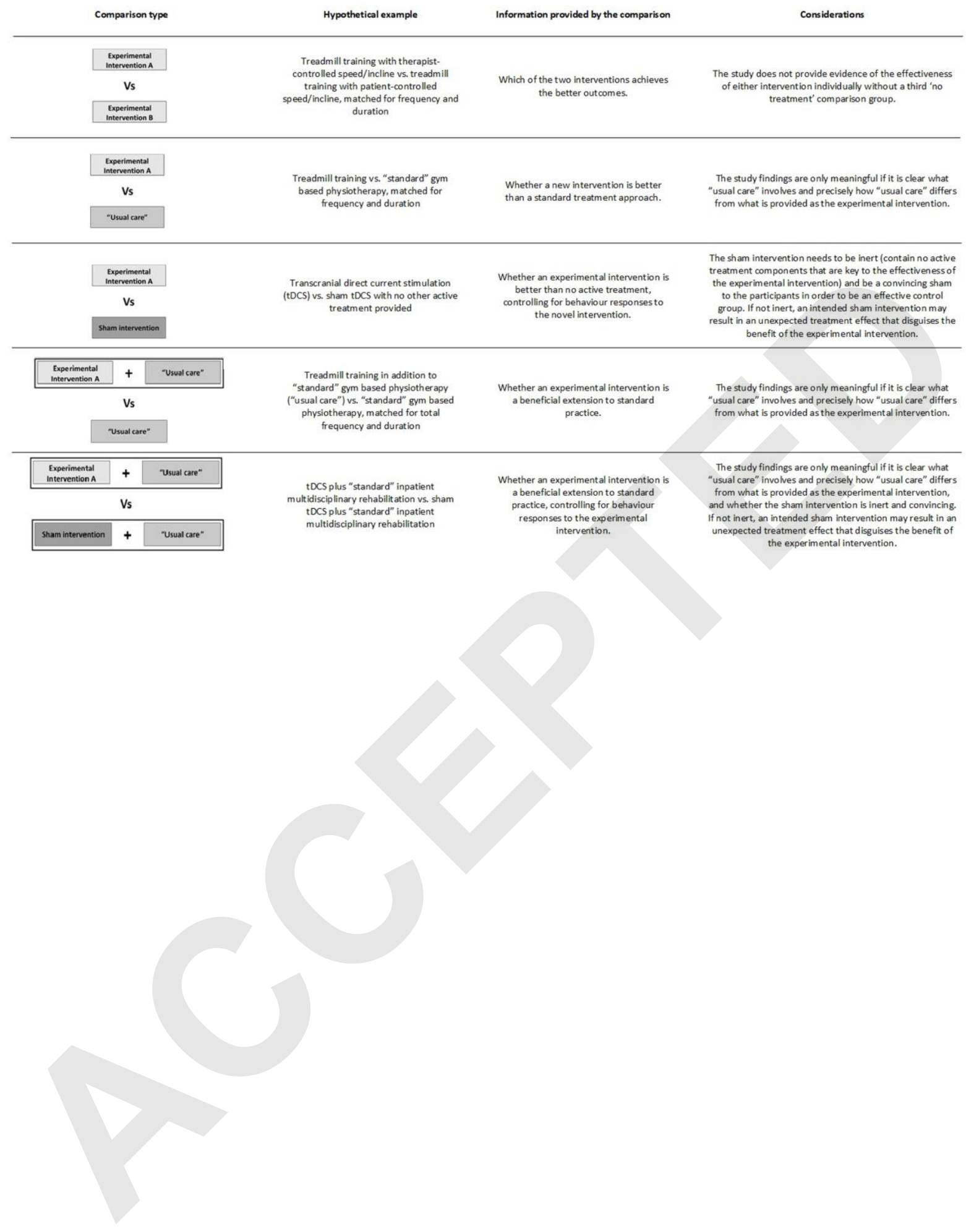

Copyright (@ 2019 Wolters Kluwer Health, Inc. Unauthorized reproduction of this article is prohibited. 
Table 1: Glossary of terms related to trial design

\begin{tabular}{|c|c|}
\hline Term & Description \\
\hline Cluster RCTs & $\begin{array}{l}\text { RCTs where randomization of participants occurs at the level of a } \\
\text { group (or "cluster") such as a ward, hospital or healthcare service, } \\
\text { rather than at the level of individual study participants. }\end{array}$ \\
\hline Equivalence trials & $\begin{array}{l}\text { Clinical trials where the aim is to determine if "one (typically } \\
\text { new) intervention is therapeutic similar to another, usually an } \\
\text { existing treatment" (p.1152) }\end{array}$ \\
\hline Harms & Adverse health consequences of an intervention. ${ }^{18}$ \\
\hline $\begin{array}{l}\text { Multi-arm parallel- } \\
\text { group randomized } \\
\text { trials }\end{array}$ & Clinical trials that involve more than two comparison groups. ${ }^{31}$ \\
\hline N-of-1 trials & e participant; a single case study. ${ }^{14}$ \\
\hline Non-inferiority trials & $\begin{array}{l}\text { Clinical trials where the aim is to determine if "a new treatment is } \\
\text { no worse than a reference treatment" (p.1152-1153) }\end{array}$ \\
\hline $\begin{array}{l}\text { Randomised crossover } \\
\text { trials }\end{array}$ & $\begin{array}{l}\text { Clinical trials where "each individual... recieves multiple } \\
\text { interventions but in a random order... In this way, each participant } \\
\text { acts as his or her own control." (p.2) }{ }^{19}\end{array}$ \\
\hline Superiority trials & $\begin{array}{l}\text { Clinical trials where the aim is to determine if one (typically new) } \\
\text { intervention is therapeutically better than another (usually } \\
\text { existing) treatment or control intervention. }\end{array}$ \\
\hline Unit of analysis & The major element (the "who" or "what") that is analyzed in a \\
\hline
\end{tabular}




\begin{tabular}{|l|l|}
\hline & $\begin{array}{l}\text { study. For example, this could be at the level of an individual cell, } \\
\text { an individual person, or at the level of group of people. }\end{array}$ \\
\hline Within person trials & $\begin{array}{l}\text { Clinical trials that involve conditions that affect two or more body } \\
\text { sites, allowing randomization to occur "within" participants at the } \\
\text { level of the body site. }\end{array}$ \\
\hline
\end{tabular}

$\mathrm{RCT}=$ randomized controlled trial 
Table 2: Summary of statements related to comparison groups in the CONSORT 2010 Statements and current extensions

\begin{tabular}{|c|c|}
\hline Standard & Reference documents \\
\hline Title and abstract & \\
\hline $\begin{array}{l}\text { 1. Authors should consider including information on } \\
\text { the comparison group as well as the intervention } \\
\text { group in the title. }\end{array}$ & CONSORT- \\
\hline $\begin{array}{l}\text { 2. Authors should report the essential features of both } \\
\text { the experimental and comparison interventions in } \\
\text { the abstract. }\end{array}$ & CONSORT-Al \\
\hline $\begin{array}{l}\text { 3. Authors should report the number of participants } \\
\text { randomized to each group in the abstract }\end{array}$ & CONSORT-Abstract $^{29}$ \\
\hline Introduction and background & \\
\hline $\begin{array}{l}\text { 4. If authors intent a trial to be a non-inferiority or } \\
\text { equivalence trial they should provide a rationale for } \\
\text { the hypothesised benefit of the experimental (new) } \\
\text { intervention over the comparison (established) } \\
\text { intervention. }\end{array}$ & CONSORT-NET $^{30}$ \\
\hline $\begin{array}{l}\text { W. When a trial contains more than two groups (e.g. } \\
\text { one experiment group and two different control } \\
\text { groups), the authors should state their intended } \\
\text { comparisons and provide a rationale for studying } \\
\text { each of these. Where authors plan to conduct } \\
\text { multiple comparisons, they should state their }\end{array}$ & CONSORT-MAPG $^{31}$ \\
\hline
\end{tabular}




\begin{tabular}{|c|c|}
\hline primary comparison(s). & \\
\hline 6. Methods & \\
\hline $\begin{array}{l}\text { 7. Authors should report whether they designed their } \\
\text { trial to assess the superiority, equivalence, or non- } \\
\text { inferiority of the interventions. }\end{array}$ & $\begin{array}{l}\text { CONSORT-SPI; }{ }^{33,43-45} \\
\text { CONSORT-NET }^{30}\end{array}$ \\
\hline $\begin{array}{l}\text { 8. Authors should report on the delivery and } \\
\text { uptake/implementation of comparison interventions } \\
\text { in as much detail as the experiment intervention, to } \\
\text { allow replication. }\end{array}$ & $\begin{array}{l}\text { CONSORT } 2010 \text { Statement; }{ }^{8,47} \\
\text { CONSORT-PT; }{ }^{32} \text { CONSORT- } \\
\text { SPI; }{ }^{33,43-45} \text { CONSORT-NPI; }{ }^{35} \\
\text { STRICTA } ;{ }^{48} \text { TIDieR }^{36}\end{array}$ \\
\hline $\begin{array}{l}\text { 9. Authors should avoid the label "usual care" to } \\
\text { describe comparison groups. }\end{array}$ & CONSORT-SPI $^{33,43-45}$ \\
\hline $\begin{array}{l}\text { 10. If the comparison group is to receive "usual care", } \\
\text { it is important to describe thoroughly what that } \\
\text { constitutes, so readers can compare this to care in } \\
\text { their own or other settings. }\end{array}$ & $\begin{array}{l}{\text { CONSORT } 2010 \text { Statement }^{8,47}} \text {; } \\
\text { CONSORT-PT }^{32}\end{array}$ \\
\hline $\begin{array}{l}\text { 11. Authors should report a rationale for the selection } \\
\text { of the comparison intervention. }\end{array}$ & STRICTA $^{48}$ \\
\hline $\begin{array}{l}\text { 12. Authors should report the expected mechanisms of } \\
\text { action (theory of change; programme theory; causal } \\
\text { pathway) for control interventions as well as } \\
\text { treatment interventions, preferably a priori, in the } \\
\text { trial registration and protocol. }\end{array}$ & CONSORT-SPI ${ }^{33,43-45}$ \\
\hline $\begin{array}{l}\text { 13. Authors should report whether the same or different } \\
\text { people delivered the experimental and comparison } \\
\text { intervention, whether providers were nested within }\end{array}$ & $\begin{array}{l}\text { CONSORT-SPI }^{33,43-45} ; \\
\text { CONSORT-NPI }^{35}\end{array}$ \\
\hline
\end{tabular}




\begin{tabular}{|c|c|}
\hline $\begin{array}{l}\text { intervention groups, and the number of participants } \\
\text { assigned to each provider. }\end{array}$ & \\
\hline $\begin{array}{l}\text { 14. Where different providers are allocated to different } \\
\text { treatment groups, authors should provide a } \\
\text { description of care providers (for example, case } \\
\text { volume, qualification, and expertise) and centers } \\
\text { (volume) in each group. }\end{array}$ & CONSORT-NPI $^{35}$ \\
\hline $\begin{array}{l}\text { 15. For equivalence or non-inferiority trials, authors } \\
\text { should report any differences between the } \\
\text { comparison intervention in the trial and the } \\
\text { reference treatment in previous trials on which } \\
\text { efficacy of the comparison intervention was } \\
\text { established. }\end{array}$ & $\mathrm{CC}$ \\
\hline $\begin{array}{l}\text { 16. Authors should report whether the comparison } \\
\text { intervention is the current standard of care for all } \\
\text { people in the context where they conducted study, } \\
\text { and whether it has equity implications. Where a } \\
\text { best practice intervention is not available in a } \\
\text { resource poor setting, a rationale for using a } \\
\text { 'second best' comparator may be justifiable. }\end{array}$ & CONSORT-Equity $^{49}$ \\
\hline $\begin{array}{l}\text { 17. Authors should report the allocation ratio to groups } \\
\text { and its rationale if the allocation ratio is unequal. }\end{array}$ & $\begin{array}{l}\text { CONSORT-MAPG }^{31} \\
\text { CONSORT-SPI }^{33,43-45}\end{array}$ \\
\hline $\begin{array}{l}\text { 18. For cluster RCTs, if the unit of analysis is the } \\
\text { individual participants not the cluster, and if it is } \\
\text { possible that the intervention will significantly }\end{array}$ & CONSORT-CT $^{46}$ \\
\hline
\end{tabular}




\begin{tabular}{|c|c|}
\hline $\begin{array}{l}\text { affect the intracluster correlation, publishing the } \\
\text { intracluster coefficient for the primary outcome } \\
\text { measure from both the comparison and intervention } \\
\text { interventions may be useful. }\end{array}$ & \\
\hline $\begin{array}{l}\text { 19. Where trials have more than two comparison } \\
\text { groups (e.g. one experiment group and two } \\
\text { different control groups), authors should report the } \\
\text { planned sample size with details of how it was } \\
\text { determined for each primary comparison. }\end{array}$ & CONSORT-MAPG $^{31}$ \\
\hline $\begin{array}{l}\text { 20. Where trials have more than two comparison } \\
\text { groups (e.g. one experiment group and two } \\
\text { different control groups), authors should explicitly } \\
\text { state if no adjustments were made for multiple } \\
\text { comparisons in the statistical methods used, and if } \\
\text { adjustments were made, report the method used. }\end{array}$ & CONSORT-MAPG $^{31}$ \\
\hline Results & \\
\hline $\begin{array}{l}\text { 21. Authors should report the dates defining periods of } \\
\text { recruitment and follow-up. If these dates differ } \\
\text { across treatment groups (e.g. groups were dropped } \\
\text { or added in trials with more than two groups), the } \\
\text { reasons for the differences and any statistical } \\
\text { implications should be described. }\end{array}$ & CONSORT-MAPG $^{31}$ \\
\hline $\begin{array}{l}\text { 22. Authors should report any qualitative analyses, } \\
\text { where used, to investigate processes of change, } \\
\text { implementation processes, contextual influences, }\end{array}$ & CONSORT-SPI ${ }^{33}$ \\
\hline
\end{tabular}




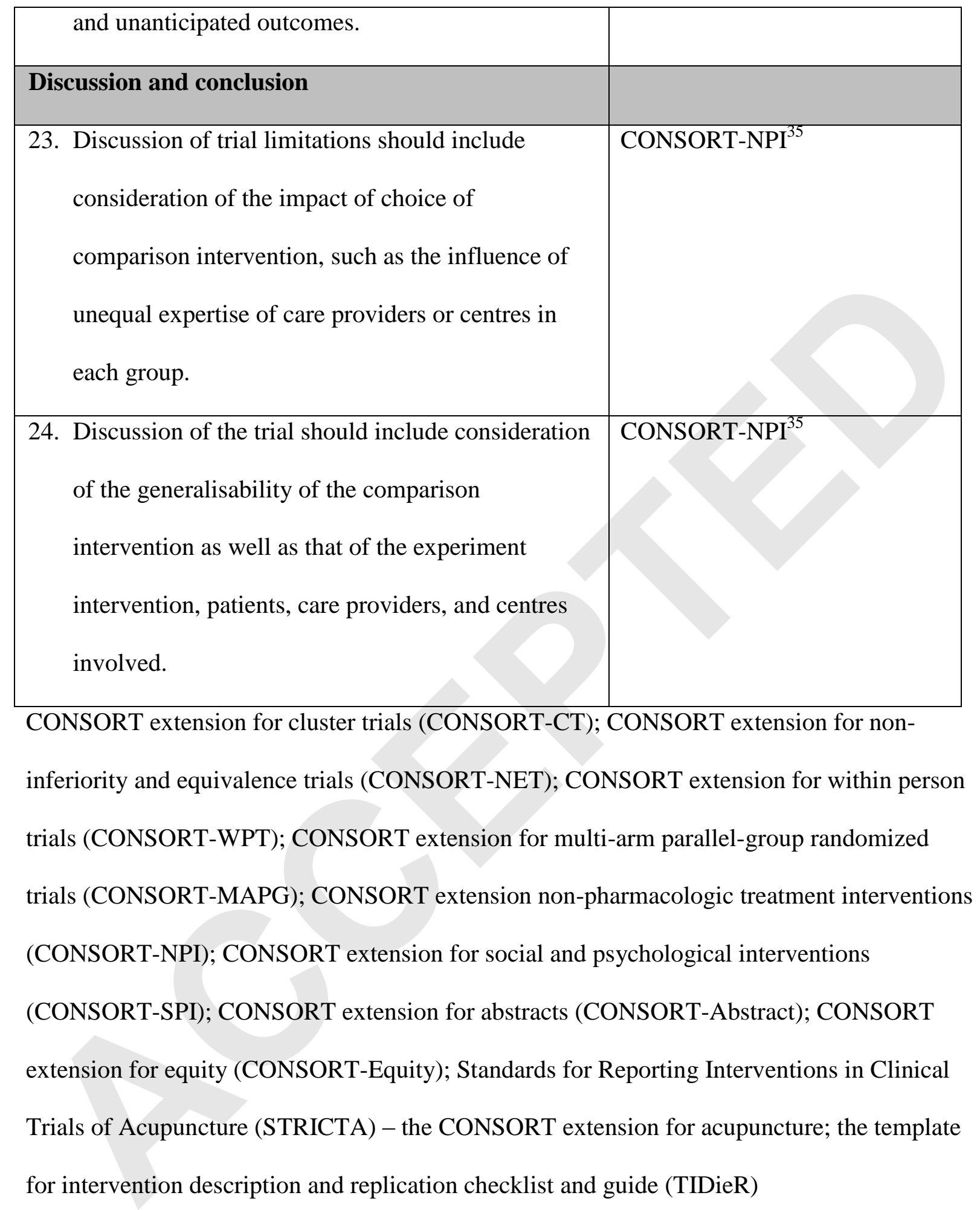

